\title{
Linear perioral spontaneous atrophic scars (atrophia maculosa varioliformis cutis) giving purse string appearance in a 36 year female
}

\author{
Reena K. Sharma ${ }^{1}$, Mudita Gupta ${ }^{2}$, Lalita Negi ${ }^{3}$, Samriti Sood ${ }^{2}$
}

${ }^{1}$ Department of Dermatology, Dr RPGMC, Tanda, India, ${ }^{2}$ Department of Dermatology, Venereology and Leprosy, IGMC, Shimla, India, ${ }^{3}$ Department of Pathology, IGMC, Shimla, India

Corresponding author: Dr. Mudita Gupta, E-mail: muditadrgupta@yahoo.com

\begin{abstract}
Spontaneous atrophic scarring of face is characterized by an idiopathic, non-inflammatory macular atrophy that typically occurs on the face. It usually occurs spontaneously over the face of children or young adults. The shallow atrophic scars have sharp margins and may be linear, rectangular or varioliform. Inheritance is usually autosomal dominant. The condition seems common, however less reported in literature. We are reporting a case of superficial linear, bilateral atrophoderma over face (perioral region) in a 36 years female, giving a purse string appearance.
\end{abstract}

Key words: Atrophoderma, linear, spontaneous

\section{INTRODUCTION}

Spontaneous atrophic scarring of face is characterized by an idiopathic, non-inflammatory macular atrophy that typically occurs on the face. It was first described by Heidingsfeld in 1918 as atrophia maculosa varioliformis cutis (AMVC) [1]. There is development of spontaneous macular atrophy in the absence of preceding trauma or inflammation. It usually occurs over face but lesions have been described over other parts of body [2]. It is more commonly seen in children and young adults [3]. The shallow atrophic lesions have sharp margins and may be linear, rectangular or varioliform. We are reporting a case of linear spontaneous atrophoderma, over perioral region giving typical purse string appearance without scleroderma.

A 36-year female presented with pruritus over body of 2 weeks duration. We noticed linear scars over her face and on further interrogation she gave history of spontaneous, painless and gradually developing scars at the age of 14-16 years. There was no history of preceding erythema, itching or trauma before the development of these scars. The female was otherwise healthy without any systemic complaints. Family history was unremarkable. On examination, multiple linear, superficial atrophic bilaterally symmetrical scars of variable size ranging from $1 \times 0.1$ to $3 \times 0.2 \mathrm{~cm}$ were present periorally around lips, angle of mouth extending upto chin in a Blaschkoid pattern (Fig. 1). This was giving a appearance simulating purse string, as seen in scleroderma. There was no evidence of sclerosis over face or anywhere else over body. Depressions were barely perceptible on palpation. She had excoriated popular lesions over body suggestive of scabies. Her routine investigations were normal. Histopathology showed mild epidermal thinning, minimal lymphocytic infilterate in the dermis without any changes of sclerosis or elastin degeneration. She was treated for scabies and given topical retinoids for atrophic scars without any significant improvement at 3 months of follow up, after that she never returned.

We noticed similar linear, bilaterally symmetrical atrophic lesions over cheeks in a young adult, who came to India for studies from South Africa, but on

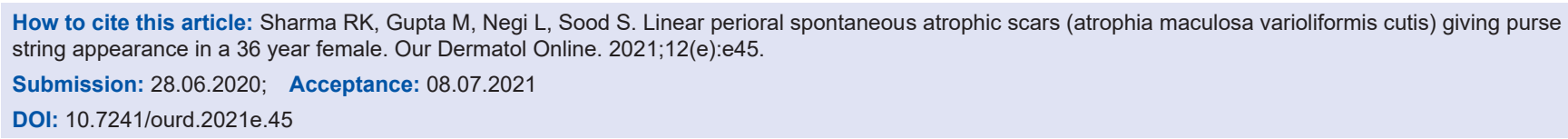




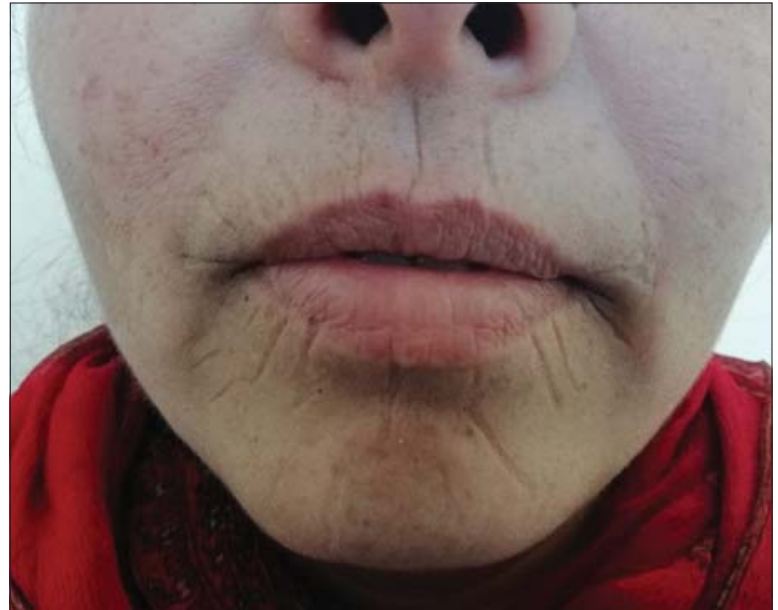

Figure 1: Linear bands of superficial atrophy in perioral region in a 36 year old female

probing it was found that it was self induced due to local tradition of facial scarification for the purpose of specific identification and beautification (Fig. 2).

\section{DISCUSSION}

Spontaneous atrophic scarring also known as Atrophia maculosa varioliformis cutis (AMVC), is an idiopathic, asymptomatic atrophic scarring of skin, generally seen in adolescents or young adults. Face especially cheeks and perioral region are the most common sites involved, however, it can be seen over other body parts also $[2,4]$. The etiology of AMVC is not exactly known, bur various hypothesis have been proposed. Familial cases have been reported suggesting it to be an inherited disorder. It has been reported with hepatic billiary atresia so the role of nutritional deficiency due to hepatic involvement is suggested, while there are also reports of its association with pachydermodactyly, however these associations may be only co-incidental $[5,6]$. In our patient there was no family history and no associated dermatological or systemic involvement.

The diagnosis of AMVC is mainly made on a clinical basis. The histological features are nonspecific, with a relatively normal dermis, a slight decrease or fragmentation of the elastic fibers in papillary dermis, an absence of fibrosis and little or no inflammation below the epidermis [6].

The differential diagnosis includes sleroderma, linear atrophoderma of Moulin, atrophoderma vermiculatum, post-inflammatory atrophy. There was no evidence of sclerosis over face or any other part of body nor were any symptoms of scleroderma. Linear atrophoderma of

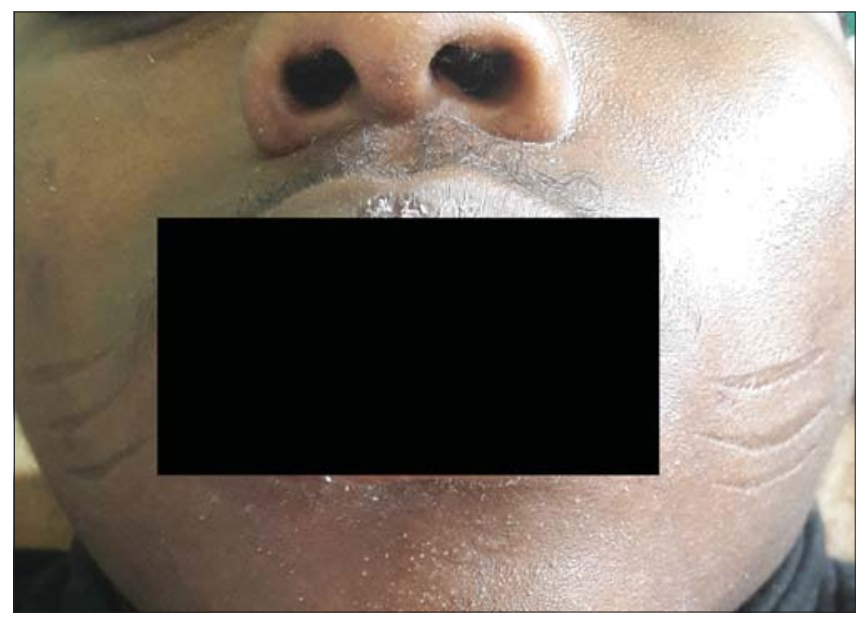

Figure 2: Linear superficial atrophic bands (self induced) as traditional in an young adult male

Moulin also presents with linear atrophic lesions along blaschkoid pattern but, usually lesions are unilateral, asymmetrical, hyperpigmented, depressed, and trunk is the most common site involved [7]. Atrphoderma vermiculatum is associated with keratotic papules and honeycomb atrophy [8]. In post-inflammatory hyperpigmentation and scarring, a history of trauma /inflammation is present. In our patient, there were shallow atrophic, bilaterally symmetrical perioral linear bands.

Treatment of AMVC is unsatisfactory. Tretinoin, collagen injections, dermabrasion or laser resurfacing techniques may theoretically help improve the facial scarring. Due to benign and non-progressive nature of the condition, patient can be reassured.

\section{CONCLUSION}

Atrophia maculosa varioliformis cutis is an idiopathic, asymptomatic atrophic scarring of skin, usually seen in adolescents or young adults. This is an underreported entity in literature probably due to its asymptomatic, nonprogressive nature.

\section{Consent}

The examination of the patient was conducted according to the principles of the Declaration of Helsinki.

The authors certify that they have obtained all appropriate patient consent forms, in which the patients gave their consent for images and other clinical information to be included in the journal. The patients understand that their names and initials will not be published and due effort will be made to conceal their identity, but that anonymity cannot be guaranteed. 


\section{REFERENCES}

1. Heidingsfeld ML. Atrophia maculoso varioliformis cutis. J Cutan Dis. 1918;36:285-8.

2. Vollono L, Donati M, Muscardin L, Panetta C, Mercuri SR, Donati P. Atrophia maculosa varioliformis cutis: a rare variant of superficial morphea? J Eur Acad Dermatol Venereol. 2019;33:e415-8.

3. Breathnach SM, McGrath JA. Wound healing. In: Burns T, Breathnach S, Cox N, Griffiths C, editors, Rooks textbook of dermatology. 9th ed. Oxford: Blackwell Science Ltd; 2016. p. 10.1-10.12.

4. Sharma RK, Gupta M, Gulati A. Linear perioral atrophoderma along Blaschko's lines- a retrospective study describing 14 cases of atrophia maculosa varioliformis cutis. Aus J Dermatol. 2021:62:e62-4.

5. Sethy M, Sachan S, Srinivas CR, Sahu S. Atrophia maculosa varioliformis cutis: A case report. Indian Dermatol online J.
2021;12:346-8.

6. EH Kim, HY Kang. A Case of atrophia maculosa varioliformis cutis. Ann Dermatol. 2008;20:244-6.

7. Wongkietkachorn K, Intarasupht J, Srisuttiyakorn C, Aunhachoke K, Nakakes A, Niumpradit N. Linear atrophoderma of moulin: a case report and review of the literature. Case Rep Dermatol. 2013;5:11-4.

8. Lee YC, Son SJ, Han TY, Lee JH. A Case of atrophoderma vermiculatum showing a good response to topical tretinoin. Ann Dermatol. 2018;30:116-8.

Copyright by Reena K. Sharma, et al. This is an open access article distributed under the terms of the Creative Commons Attribution License, which permits unrestricted use, distribution, and reproduction in any medium, provided the original author and source are credited.

Source of Support: Nil, Conflict of Interest: None declared. 